\title{
MITO E HISTORIA DEL CID EN LA NOVELA EL SEÑOR DE LAS DOS RELIGIONES DE JUAN JOSÉ HERNÁNDEZ
}

\author{
MYTH AND HISTORY OF CID IN THE NOVEL LORD OF TWO RELIGIONS \\ BY JUAN JOSÉ HERNÁNDEZ
}

\author{
Peter Ivanov Mollov \\ Universidad de Sofia San Clemente de Ohrid \\ pmollov@abv.bg
}

Fecha de recepción: 06-04-2017

Fecha de aceptación: 20-12-2017

\section{RESUMEN}

El texto constituye un análisis literario de la novela histórica de Juan José Hernández El señor de las dos religiones. Se pretende analizar cómo el autor traza la imagen de Rodrigo Díaz de Vivar y los diversos aspectos de su personalidad presentándolo desde el punto de vista del rey Alfonso VI, el narrador de la novela. Nos proponemos asimismo indagar hasta qué punto la imagen literaria del Cid creada por el novelista se corresponde con la verdad histórica, a fin de valorar la historicidad de la obra.

Palabras Clave: Cid, novela histórica, análisis.

\section{Abstract}

The text consists in a literary analysis of the historical novel Lord of two religions by Juan José Hernández. Our purpose is to analyse how the author traces the image of Rodrigo Díaz de Vivar and the diverse aspects of his personality presenting the hero from King Alfonso VI's point of view, as narrator of the novel. Our purpose is also to investigate if the 
literary image of Cid created by the novelist corresponds with the historical truth, in order to value the historicity of the work.

KEY WORDS: Cid, historical novel, analysis.

En las últimas décadas se observa un boom de la novela histórica a escala mundial, en cuanto a la actividad editorial y el interés de los lectores, siendo las novelas ambientadas en la época medieval las más numerosas. Antonio Huertas Morales señala que hay un creciente interés general hacia la historia que penetra en distintas áreas: de la literatura pasa a la cultura de masas —el cine, los cómics, los videojuegos- (2015: 20). Al igual que en el siglo XIX, las editoriales responden al gusto del púbico creando series de novelas históricas que se divulgan a través de abonos o en los quioscos (una nueva variante de la tradición folletinesca), promueven premios literarios a los escritores que cultivan este género.

¿A qué se debe el interés masivo hacia la novela histórica y especialmente la ambientada en la Edad Media? Huertas Morales señala diversos factores: el agotamiento del modelo realista y social, la influencia de otras literaturas, el impacto comercial de algunas obras, la búsqueda de los valores tradicionales. Y el interés hacia la temática medieval se explica teniendo en cuenta que se trata de una época que abarca todo un milenio de nuestra historia, pero tiene que ver también con la influencia de la novela histórica romántica sobre la actual; además, las escasas fuentes de información convierten el Medievo en un fondo idóneo para una trama ficcional (2015: 25).

Cabe subrayar que la novela histórica actual tiene un carácter heterogéneo, como lo es también el público lector. Los lectores más exigentes esperan que una novela histórica sea altamente realista y se atenga a los datos históricos. Otros aprecian más la intriga, el misterio, el esoterismo. El elemento histórico se puede integrar en diferentes géneros: novela de aventuras, policíaca, biográfica, feminista, triller, fantástica.

La novela histórica actual postmoderna, según Raquel Crespo, somete la historia a una revisión y subjetivación, mostrando la naturaleza ficcional de sus enunciados y, en buen número de ocasiones, los pone en entredicho o los parodia (2015: 39). En efecto, a pesar de la diversidad que hemos señalado, el común denominador de las novelas históricas de las últimas décadas es la consciencia de los autores de la imposibilidad de conocer - y de ahí de narrar- los sucesos históricos de manera totalmente objetiva, la aceptación de las limitaciones, del relativismo que caracterizan nuestros conocimientos sobre el pasado. De ahí que los escritores recurran a la imaginación, interpretando las fuentes, llenando las lagunas, presentando posibles versiones de los acontecimientos, así como múltiples puntos de vista.

No es de sorprender que en las novelas españolas de tema medieval haya un marcado interés por el Cid, sin duda el personaje más mitologizado de la historia española de la Edad Media. Además, Raquel Crespo encuentra una similitud entre Rodrigo Díaz y el hombre moderno: él era «un nómada», «un desarraigado», un espíritu itinerante» como el hombre de hoy (2015: 46-47). Esta comparación no carece de fundamento, pero no debemos olvidar que si el Cid se ha convertido en héroe y mito y si continúa impresionándonos, es por 
su dedicación a una misión nacional y religiosa y no por su capacidad de adaptación, típica del hombre moderno y relacionada con el creciente individualismo.

Una característica que comparten las novelas contemporáneas sobre el Cid es el enfoque desmitificador, la tendencia a soslayar los episodios claramente legendarios, que tienen primacía en las obras de épocas pretéritas que recrean su imagen, y el intento de dar una idea veraz y realista de los acontecimientos y los personajes históricos de acuerdo con las fuentes más fidedignas. Así el Cid aparece despojado de su halo de caballero perfecto y se nos presenta como un hombre de su tiempo, dependiente de las circunstancias históricas y sociales en que le tocó vivir, y a la vez dotado de capacidades excepcionales que le ayudaron a destacar, a dejar su impronta en la historia.

La novela que nos proponemos analizar es la primera de Juan José Hernández, cuya biografía impresiona con la diversidad de sus intereses y ocupaciones: los negocios, las influencias interculturales, el flamenco. En 1997 crea la Fundación Culturas para el Diálogo donde se debaten diversos problemas acerca de las relaciones entre culturas.

El señor de las dos religiones del año 2005 constituye una biografía novelada del rey Alfonso VI en que predomina la forma autobiográfica, ya que el narrador es el propio monarca (excepto algunos capítulos en que hablan otros personajes históricos). Llama la atención la excelente preparación historiográfica del novelista, combinada con un penetrante «autoanálisis» de las ambiciones, las aspiraciones, los afanes, las dudas, los temores y las pasiones del rey. Precisamente en el elemento psicológico, en las reflexiones del personaje sobre la vida en general, sobre su época, sobre las personas de su entorno y sus relaciones con ellas, así como sobre sus propios motivos para tomar una u otra decisión reside el mayor logro del autor. Pese a la alta dosis de interpretación personal —inevitable — del novelista, la narración en nombre del protagonista impide que esta novela, carente de ficción, se convierta en un relato historiográfico.

Aun sin ser la figura central, Rodrigo Díaz tiene su lugar importante en la narración y la manera de presentar su imagen en la novela es sumamente interesante, ya que, a diferencia de otras obras dedicadas al héroe castellano, aquí lo vemos a través de los ojos del rey, lo cual ofrece otra perspectiva, a veces muy diferente, a sus acciones y las relaciones entre los dos.

Para Alfonso el joven Rodrigo es el fiel amigo de su hermano, y más tarde alférez de sus tropas. Él cuenta, sin un atisbo de reproche, que precisamente Rodrigo fue el pricipal opositor a su coronación tras la infausta muerte de Sancho debido a las sospechas de que estaba implicado en su asesinato, mas no dice nada de su papel en la jura de Santa Gadea. Quizá el autor ha querido sugerir que la leyenda que atribuye a Rodrigo la osadía de exigir al rey que prestara juramento no es más que una invención. Sabemos que no hay datos históricos que confirmen este episodio de la vida del héroe y lo más probable es que fuera uno más entre los nobles castellanos que aceptaron, pero no sin reservas, al nuevo soberano.

El rey explica sus motivos de concertar el matrimonio entre Rodrigo y Jimena con el deseo de atraerlo a su lado, elevándolo en la jerarquía al casarlo con una representante de la alta nobleza. Por la misma razón la ceremonia nupcial es solemne, están presentes los no- 
bles más importantes en la corte, así como el rey y sus hermanas Urraca y Elvira, y dos de los principales adversarios de Rodrigo —Pedro Ansúrez y García Ordóñez — son elegidos para ser testigos.

Asimismo el monarca designa a Rodrigo para juzgar en pleitos de poca importancia, junto con otro juez que no es de Castilla y es hábil político, «a fin de hacerle ver la necesidad de tener en cuenta las razones políticas y no sólo los intereses militares» (p. 86).

En estrecha relación con lo antedicho están los sucesos que se desarrollaron durante el conflicto entre los reinos de Sevilla y Granada en que la tropa liderada por Cid se enfrenta con la dirigida por García Ordóñez. El rey Alfonso transmite los hechos de una forma bien distinta de la que conocemos de otras obras literarias que los registran. El monarca envía a ambos con una doble misión: además de cobrar en su nombre los tributos debidos, el primero tiene que intimidar a los sevillanos, demostrando la potencia militar de Castilla, y el segundo, estimular las ambiciones expansionistas de Granada a costa de Sevilla, cuyas fuerzas Alfonso quería debilitar. La intervención de Rodrigo a favor de Sevilla y su victoria estaban en disonancia con los planes del monarca. En sus reflexiones sobre lo ocurrido, el rey reconoce las cualidades de Rodrigo como líder militar, así como su rectitud, pero le reprocha la falta de dotes diplomáticas que «lo convertía en un peligro político cuando su misión no era solo hacer la guerra» (p. 98). Muy indicativa del punto de vista de Alfonso con respecto a sus relaciones con el héroe es la siguiente declaración: «Desde el principio quise ser su amigo y de él recibí lealtad y obediencia, pero no amistad» (p. 99). Según Alfonso, los nobles influyentes le obligaron a tomar en consideración sus acusaciones contra Rodrigo, aun cuando él mismo desconfiaba de los rumores de que éste se hubiera apropiado de parte de las parias entregadas por el rey de Sevilla.

El Cid muestra la misma impulsividad y propensión a actuar por su cuenta desatendiendo la situación política cuando invade el reino de Toledo, cuyo soberano era aliado de Alfonso. El monarca señala que su vasallo vuelve a crear problemas, dando pie a que sus enemigos en la corte exijan que sea castigado. La novela nos ofrece una versión interesante del destierro de Rodrigo que no encontramos en otras obras: según el rey, él se ve forzado a desterrar a Rodrigo, pero antes celebra una entrevista con él para explicarle la situación y afirma que Rodrigo entendió sus razones y «o no quiso o supo oponerse a ellas» (p. 103). El destierro está presentado como un trato secreto entre los dos: el Cid continuaría sirviendo a su rey, pero fuera del reino durante cierto tiempo; Alfonso le convence de que entre al servicio del rey de Zaragoza para defenderle de las ambiciones de otros monarcas, hasta que el propio Alfonso esté en condiciones de pretender su dominio. No hay testimonios históricos de la existencia de un trato así entre los dos ${ }^{1}$, lo cual no significa que no pudiera existir; sin embargo, esta versión no sale del ámbito de la invención novelesca, aun cuando parezca posible, ya que el modo de actuar de Rodrigo mientras está al servicio del rey de Zaragoza permite semejante conjetura: el Cid defiende a Zaragoza de amenazas externas, pero está dispuesto a apoyar al monarca castellano en caso de necesidad, como en

\footnotetext{
${ }^{1}$ Nos basamos en la Historia Roderici, la fuente cristiana más cercana a la época del Cid (siglo XII) y en el estudio fundamental de Ramón Menéndez Pidal La España del Cid.
} 
Rueda. Según la versión de Hernández, después de su encuentro allí, Rodrigo desea volver a Castilla, pero Alfonso le convence de que los intereses de su reino requieren que siga sirviendo a Al-Mutamín en Zaragoza. Cuando más tarde, bajo el gobierno del hijo de Al-Mutamín, Al-Mustaín, quien se niega a pagar tributos a Castilla, Alfonso decide atacar Zaragoza, él avisa en secreto al Cid de sus intenciones y éste se dirige al norte para estar fuera de la ciudad cuando lleguen las tropas castellanas.

En consonancia con esta versión acerca de las relaciones entre Rodrigo y Alfonso, éste explica el hecho de no recurrir a la ayuda de su vasallo en la batalla de Sagrajas, en que los cristianos son derrotados, diciendo que se sentía seguro de la victoria tras su alianza con Aragón, Francia e Italia, es decir, su decisión no tiene que ver con las supuestas desavenencias entre los dos, ni con la soberbia del monarca.

Hemos de reconocer que la interpretación de Hernández hace que parezca más lógica la reconciliación formal entre rey y vasallo en las afueras de Toledo y la generosidad que muestra Alfonso concediéndole a Rodrigo los derechos de posesión sobre sus futuras conquistas. Semejante gesto parecería al menos sorprendente, si sus relaciones hubieran sido tan malas como tradicionalmente se cree. Es así como Alfonso explica su generosidad inusual: «Con ello daba una base legal a los deseos de poder de Rodrigo, y quizá también a sus mal disimuladas ilusiones sociales» (p. 154).

Según la novela, el verdadero conflicto entre ellos se produce cuando el Cid no acude a apoyarle en la defensa de Aledo $^{2}$. La rabiosa reacción del rey, pese a los intentos de Rodrigo de explicar sus razones, se debe, según sus palabras, a que los hechos eran indiscutibles y los nobles le presionaban a castigar al héroe. «Desde entonces - declara Alfonsoactuaría con total independencia, y si algo conquistaba lo podría hacer en su nombre» (p. 158).

No obstante, cuando el Cid emprende su campaña en el Levante ibérico, Alfonso señala: «De alguna manera me había suplantado en lo económico y en lo político, aunque yo nunca dejé de tener la sensación de ser su rey. Él, estoy seguro, nunca dejó tampoco de tenerla» (p. 160). Cuando el rey de Zaragoza y el conde de Barcelona tratan de aliarse con Alfonso contra el Cid, el monarca castellano se niega, prefiriendo que Valencia quede en manos de su exvasallo. Al enterarse de la derrota que éste ha infligido a las tropas, mucho más numerosas, del conde de Barcelona, Alfonso no oculta su admiración ante el talento de Rodrigo como estratega militar.

Los dos se reconciliarán y volverán a enemistarse en la campaña contra Granada «como amantes a la vez queridos y odiados» (así es como Alfonso califica los altibajos en sus relaciones) (p. 172). Después, según el rey, Rodrigo empieza a comportarse como un monarca que hace y deshace alianzas a su discreción ${ }^{3}$. Con todo, él nunca se enfrenta con el rey, «aunque como vasallo desterrado pudiera hacerlo sin atentar contra su honor ni con-

\footnotetext{
${ }^{2}$ Las razones por las cuales la hueste de Rodrigo no se une al ejército real siguen siendo discutibles.

${ }^{3}$ Richard Fletcher confirma esta constatación, diciendo que «entre 1094 y 1099 Rodrigo no actuó en otro beneficio que el suyo propio» (1989: 190).
} 
tra las leyes» (p. 175). Pero los lazos de lealtad que todavía le unen a Alfonso no le impiden atacar a García Ordóñez. El rey considera que este acto del Cid muestra más bien su ira contra él que su odio hacia el conde.

La novela describe brevemente la asolación de las tierras del conde por los guerreros del Cid y el rey comenta que no esperaba semejante crueldad por su parte. La complicada situación política tras la invasión almorávide le hace al rey olvidar lo ocurrido para buscar otra vez la alianza con «el mejor de sus caballeros» (p. 176), una llamada a la que el Cid acude.

Alfonso reconoce que la conquista de Valencia por el Cid provoca en él sentimientos contradictorios: por una parte, alegría de la victoria, pero, por otra, celos por no haber entrado él mismo triunfante en la ciudad. Es muy probable que el rey envidiara los éxitos de Rodrigo, sobre todo contra los almorávides a quienes el monarca nunca logra vencer. Cabe subrayar que en la novela, a pesar de los conflictos entre los dos, Alfonso habla con afecto y comprensión de su vasallo. Él es consciente de sus cualidades como líder militar, pero sabe que los entresijos de la política le son ajenos. Al mismo tiempo valora sus muestras de lealtad hacia él, se da cuenta de sus esfuerzos por mantener buenas relaciones con su rey y servir a los intereses de su reino al que, pese a todas las vicisitudes, nunca deja de sentirse unido.

Una atención especial merece el breve capítulo (pp. 190-192) en que el novelista le da la palabra a Rodrigo. Las reflexiones del caballero sobre su propia vida y los incentivos que guiaban sus acciones constituyen un acertado retrato psicológico, tal vez muy próximo a la realidad. Veamos la recapitulación que hace Rodrigo hacia el final de su vida:

«Ambición y lealtad han sido dos razones fundamentales de mi vida. La primera me ha llevado a quererlo todo, el poder y la gloria, el mando sobre los hombres y la posesión de las cosas; y en la lealtad he descansado mi espíritu y he justificado muchos actos para los que no encontraba sentido. Primero profesé lealtad a Sancho, mi señor natural, el que fue mi rey y mi amigo; después, con Alfonso, por el que no sentí cariño, presté lealtad a las instituciones y a la palabra empeñada.» (p. 190)

Su dedicación a las campañas bélicas obedece a su consciencia de que ese era su destino, la vida que le estaba predestinada, pero declara que ese no fue un objetivo en sí, su afán era el enriquecimiento, la gloria y el placer de la victoria. Se da cuenta, sin un atisbo de sentimentalismo, de la faceta injusta de la guerra, de los sufrimientos que causa a personas inocentes que con su trabajo mantienen a los guerreros. Pero, paradójicamente, es en la batalla cuando cobra la certeza que le falta:

"Cuando descanso todo es confuso y sin justificación, no sé si habrá algo que tenga sentido en esta vida, pero cuando clavo las espuelas en los costados de mi caballo para medirme con otro hombre terminan todas mis dudas, sólo hay lugar en mi mente para vivir ese instante que por llenarlo todo hace que olvidemos todo.» (p. 191)

Sin duda, como cualquier ser humano, Rodrigo se planteaba el sentido de la vida, el sentido de todo lo que hacemos, invirtiendo nuestra ambición, nuestras fuerzas, nuestra 
energía. Y sentiría, como todos nosotros en algunos momentos, la sensación dolorosa de los absurdos que marcan nuestro paso por la Tierra; pero también sería consciente de que no podría vivir de otro modo, no podría renunciar a lo que sus instintos le incitaban, y aceptó su destino.

Veamos ahora la recapitulación que hace el rey después de la muerte del Cid del papel que desempeñó el héroe en su vida y de sus relaciones:

«También ha muerto Rodrigo Díaz, al que todos llaman el Cid, el hombre que alimentó mis sueños ambiciosos de victoria y proporcionó a mis noches remordimientos y cavilaciones; el guerrero poderoso y el cortesano inadaptado; el que fue vasallo fiel y no supo, tal vez porque yo no se lo facilité, ser mi amigo. Hasta su muerte ha debido pensar que fui injusto con él, aunque también pienso que él lo fue conmigo. Mi vida hubiese sido distinta sin Rodrigo, y es posible que incluso mis reinos. Sin su presencia Valencia dejará de ser un freno al ataque almorávide para convertirse en otro problema, y de no fácil solución. Indisciplinado, audaz y a veces incomprensible, ha sido uno de los pilares que ha soportado muchos de los momentos difíciles de mi reinado.» (pp. 203-204)

La novela de Juan José Hernández es una de las mejores obras en la actualidad sobre la época del Cid por compaginar la veracidad histórica y la inevitable interpretación personal a la que las lagunas en la historia obligan a acudir y sin la cual una obra literaria perdería su singularidad y su impacto. La interpretación de los hechos, del papel de los personajes históricos en ellos y de las razones que motivaron sus decisiones y sus actos que ofrece el novelista es convincente, ya que se fundamenta en la lógica y en las particularidades de la mentalidad y el carácter de los personajes en la medida en que las fuentes nos permiten conocerlos. Es de apreciar el enfoque desmitificador del autor que da la espalda a las invenciones legendarias que se han ido insertando en la historia del Cid para crear una imagen realista del héroe.

La novela, como también otras del género histórico en nuestra época postmoderna, termina afirmando la subjetividad de nuestras valoraciones. El rey Alfonso es consciente de la imposibilidad de ser imparciales cuando analizamos nuestras propias acciones y de que nuestro relato de los hechos es siempre personal, dependiente de nuestro punto de vista: «Narrar lo que cada uno de nosotros percibe como la realidad, aun con toda la honestidad posible, solamente nos conducirá a relatar nuestra visión de la realidad. [...] Con toda seguridad otros contarán la misma historia de forma tan distinta que en algunos momentos podrá parecer otra» (p. 228).

A diferencia de otras novelas históricas, el lenguaje no es arcaizante, el estilo destaca por su sencillez y claridad, lo cual potencia lo que consideramos como el mayor logro del novelista: la profundidad filosófica y psicológica de las observaciones y las reflexiones no sólo sobre los hechos históricos, sino también sobre la vida y los seres humanos en general. 


\section{REFERENCIAS BIBLIOGRÁFICAS}

Fletcher, Richard (1989). El Cid, Madrid, Nerea.

«Historia Roderici» (I983). Boletín de la Institución Fernán González, 201, pp. 339-375 (Traducción al español de Emma Falque Rey).

Huertas Morales, Antonio (2015). La Edad Media contemporánea. Estudio de la novela española de tema medieval (1990-2012), Vigo, Editorial Academia del Hispanismo.

Crespo-VILA, RaQuel (2015). «Reescrituras cidianas: Rodrigo Díaz de Vivar y la condición posmoderna», Cuadernos de Aleph 7, pp. 31-51.

HeRnández, Juan José (2005). El señor de las dos religiones, Madrid, Trotta.

Menéndez Pidal, Ramón (I969). La España del Cid, Madrid, Espasa Calpe. 